\title{
Influence of Temperature and Water Vapour Pressure on Drying Kinetics and Colloidal Microstructure of Dried Sodium Water Glass
}

\author{
Hans Roggendorf*, Matthias Fischer, Robert Roth, Reinhold Godehardt \\ Institut für Physik, Martin-Luther-Universität Halle-Wittenberg, Halle (Saale), Germany \\ Email: ${ }^{*}$ hans.roggendorf@physik.uni-halle.de
}

Received 26 December 2014; accepted 9 January 2015; published 15 January 2015

Copyright (C) 2015 by authors and Scientific Research Publishing Inc.

This work is licensed under the Creative Commons Attribution International License (CC BY). http://creativecommons.org/licenses/by/4.0/

(c) (i) Open Access

\begin{abstract}
Industrially produced sodium water glasses were dried in climates with controlled temperature and humidity to transparent amorphous water containing sodium silicate materials. The water glasses had molar $\mathrm{SiO}_{2}: \mathrm{Na}_{2} \mathrm{O}$ ratios of $2.2,3.3$ and 3.9 and were dried up to 84 days at temperatures between $40^{\circ} \mathrm{C}$ and $95^{\circ} \mathrm{C}$ and water vapour pressures between 5 and $40 \mathrm{kPa}$. The materials approached final water concentrations which are equilibrium values and are controlled by the water vapour pressure of the atmosphere and the microstructure of the solids. The microstructure of the dried water glasses was characterized by atomic force microscopy. It has a nanosized substructure built up by the silicate colloids of the educts but deformed by capillary forces. In the final drying equilibrium, the water vapour pressure of the atmosphere in the drying cabinet is equal to the reduced vapour pressure of the capillary system built up by the silicate colloids. Their size scale can be explained by the deformation of colloidal aggregates due to capillary forces.
\end{abstract}

\section{Keywords}

Concentrated Sodium Silicate Sol, Silica Colloids, Drying, Atomic Force Microscopy, Capillarity

\section{Introduction}

Sodium water glasses are commonly produced by dissolving either alkali silicate glasses in water or silica materials in $\mathrm{NaOH}$ solutions at hydrothermal conditions [1] [2]. The old literature on water glass was compiled by

"Corresponding author.

How to cite this paper: Roggendorf, H., Fischer, M., Roth, R. and Godehardt, R. (2015) Influence of Temperature and Water Vapour Pressure on Drying Kinetics and Colloidal Microstructure of Dried Sodium Water Glass. Advances in Chemical Engineering and Science, 5, 72-82. http://dx.doi.org/10.4236/aces.2015.51008 
Vail [1]; more contemporary reviews were published by Iler [3] and Falcone [4]. The structure of water glasses can be described as colloidal suspensions in aqueous sodium silicate solutions or briefly as sodium silicate sols [2] [3]. The main silicate ingredients of water glasses are colloids and monomeric or oligomeric silicatic anions or molecules. The distinction between anions and molecules on one hand and colloids on the other hand is arbitrary, since the colloids can also be regarded as large molecules. In concentrated water glasses with $R_{m}$ (=molar $\mathrm{SiO}_{2}: \mathrm{Na}_{2} \mathrm{O}$ ratio) $>2$, a cut at a diameter of $1 \mathrm{~nm}$ seems to be appropriate. Such a diameter corresponds to 10 to $11 \mathrm{SiO}_{2}$ formula units.

Colloids in water glass consist mainly of silica [5]. Iler [6] investigated colloids extracted with tetrahydrofurane from sodium silicate solution $\left(R_{m}=3.22\right.$, $\left.28.7 \mathrm{wt} \% \mathrm{SiO}_{2}\right)$ with static light scattering and found $10 \%$ monomers, $15 \%$ oligomers and $75 \%$ colloids with a diameter of about $1.8-1.9 \mathrm{~nm}$. An electric double layer at the surface of the colloids and steric effects [7] are supposed to stabilize the colloidal suspensions at basic $\mathrm{pH}$ values. The double layer consists of negatively charged $\mathrm{Si}-\mathrm{OH}$ groups covered by a layer of hydrated sodium ions. Bahlmann et al. [8] investigated the molecular content of a concentrated water glass $\left(R_{m}=4.0,25 \mathrm{wt} \%\right.$ $\mathrm{SiO}_{2}$ ) by ${ }^{29} \mathrm{Si}$ NMR spectroscopy and found that nearly $75 \%$ of the silicon atoms are present as highly polymerized $Q^{3}$ or $Q^{4}$ units which are typical of colloidal silica. Own investigations with dynamic light scattering [9] yielded particle size distributions with three or more particle size maxima at diameters between 1 and $200 \mathrm{~nm}$ even in diluted solutions with silica contents down to $1 \mathrm{wt} \%$. The smallest particle sizes having a maximum frequency density occur at diameters of $1 \mathrm{~nm}$. Nordström et al. [10] confirmed these findings by dynamic light scattering and small angle X-ray scattering but highlighted the importance of smaller oligomers, small "clusters", with diameters of approximately $1.4 \mathrm{~nm}$ as the main part of the silica. Tognonvi et al. [11] combined ${ }^{29} \mathrm{Si}$ NMR spectroscopy and small angle X-ray scattering to describe solvated silicate ions. They proposed a neutral $\mathrm{Si}_{7} \mathrm{O}_{18} \mathrm{H}_{4} \mathrm{Na}_{4}$ complex as primary building unit with a size of 0.6 to $0.8 \mathrm{~nm}$ in concentrated liquid water glasses with $R_{m}=3.4$. Halasz et al. [12] measured osmotic pressures of sodium silicate sols with up to $3 \mathrm{~mol} / \mathrm{dm}^{3} \mathrm{SiO}_{2}$ and concluded that the average silicate unit in a sodium water glass with $R_{m}=3.3$ contains about $10 \mathrm{SiO}_{2}$ units. These results on colloid sizes in sodium water glasses can be interpreted by the assumption that small primary particles form larger aggregates [6] [9].

Commercially available sodium silicate solutions are characterized by a molar $\mathrm{SiO}_{2}: \mathrm{Na}_{2} \mathrm{O}$ ratio of 2 - 4 and $\mathrm{SiO}_{2}$ contents of 25 - $30 \mathrm{wt} \%$ [1]. For some applications the materials have to be partially dried e.g. by spray drying for binder applications. Dried water glass is also a component of fire protecting materials e.g. [13]. In the application case it is heated and foams forming porous thermal insulation materials. During drying the viscosity of the solution is raised within a narrow concentration range by a few orders of magnitude as a function of the water content [1].

Results on thermal analysis of dried water glasses were published by Dent Glasser and Lee [14]. They heated their samples in open crucibles and found at least two endothermic signals in differential thermal analysis which they attributed to structural rearrangements and condensation reactions. In own investigations [15] [16], transparent, solid and amorphous materials were obtained by drying a sodium silicate solution with $R_{m}=3.27$. During heating thermal reactions occur which were investigated by combined application of simultaneous thermal analysis, electron microscopy and hot stage microscopy. One of these reactions was attributed to a sol-gel or a sol-colloidal glass transition. Based on these structural findings, a model of the structural evolution of the solutions during drying was developed [16] in accordance to structure models developed for amorphous materials with a colloidal microstructure [17]. According to this model, the sol solidifies to a dense gel by reducing the distance between the colloids until their movement is sterically hindered.

The vapour pressure of a solvent in a homogeneous solution is reduced according to Raoult's law by the dissolved matter itself. The reduction is a colligative property and depends on the number of dispersed or dissolved units. Thermodynamically, the vapour pressure reduction is due to the difference of chemical potential between water dispersed in the sol and pure water. A consequence of that difference is the increase of boiling temperature. However measurements show that this effect is limited [18]. Boiling point elevations up to $1.5^{\circ} \mathrm{C}$ for concentrated sodium silicate sols with $R_{m} \sim 1.7$ were reported. The boiling point elevations decrease with higher $R_{m}$ values. These data on boiling point elevations correspond to a vapour pressure reduction of less than $5 \%$. This small effect was explained [1] by the colloidal structure of liquid water glasses: the number of dissolved units is limited because the total number of colloids is small compared to the number of $\mathrm{SiO}_{2}$ formula units.

Dried colloidal suspensions are heterogeneous on a colloidal scale [17] and are made up of a more or less 
dense packing of colloids. The voids in this packing build up an interconnected capillary system filled with a solvent or, in the case of dried water glasses, with an aqueous solution. In such a microstructure, the vapour pressure is further reduced by the negative curvatures of the surface of the solvent in the capillary pores system [19]. The influence of capillary geometry on vapour pressure is described by the Thomson-Freundlich [19] equation-also known as Gibbs-Thomson equation [20]. It links the vapour pressure with the capillary diameters of the pore system. The drying process of porous gels was described by Brinker and Scherer [19]. They distinguished three time periods of drying. At first a constant drying rate is observed where the water evaporates directly from the surface. Later the drying front moves into the drying body with the consequence that the drying rate is decreased and the sample gets translucent due to the formation of interfaces between gas and condensed matter in the interior of the sample. In the constant rate period, the mass loss rate follows the Hertz-Knudsen equation [21]:

$$
\frac{\mathrm{d} m}{\mathrm{~d} t}=\left(p_{v}-p_{p}\right) \cdot \sqrt{\frac{m_{\text {molecule }}}{2 \pi k_{B} T}},
$$

with

$m: \quad$ mass of drying body,

$t: \quad$ time,

$p_{v}: \quad$ vapour pressure of liquid,

$p_{p}: \quad$ partial pressure of evaporating molecule in gas phase,

$m_{\text {molecule }}$ : mass of evaporating molecule,

$k_{\mathrm{B}}: \quad$ Boltzmann constant, and

$T$ : $\quad$ absolute temperature.

As a consequence, the mass loss stops when $\Delta p=\left(p_{v}-p_{p}\right)$ becomes zero. As mentioned above some applications of sodium water glasses depend on partially drying the materials. Investigating the drying kinetics will help to choose optimal drying conditions. Knowing the structure of the dried materials contributes to our understanding of the foaming behaviour relevant for intumescent layers in fire protective glazings. Therefore, results on sodium water glasses dried to mass constancy under controlled atmospheres will be presented. Especially the relations among vapour pressure during drying, temperature and residual water content were investigated. The implications of drying conditions on structure will be discussed and compared with results of structural characterizations of dried water glasses by atomic force microscopy. Also differences to normal drying processes will be discussed.

\section{Materials and Methods}

Three types of technical grade sodium water glasses with different $R_{m}$ values were used as starting materials. Their compositions and some properties are listed in Table 1. The liquid water glasses were named NaSi (for sodium and silicon) augmented by the $R_{m}$ value, for instance NaSi2.2 for the sodium water glass with $R_{m}=2.2$. The compositions were analysed by titration with $0.5 \mathrm{M} \mathrm{HCl}$ (yields $\mathrm{Na}_{2} \mathrm{O}$ content) and by loss on ignition. Impurities were neglected. $\mathrm{pH}$ was measured with a glass electrode (pH 330i, WTW, Weilheim, Germany), density by a pycnometer, refractive index by an Abbe Refractometer, and viscosity by the Ubbelohde method. All values were measured at $25^{\circ} \mathrm{C}$. The water glasses were dried in polystyrene or polytetrafluoroethylene beakers in controlled climates established in climate chambers (Hereaus Vötsch VTKR 150 and Vötsch VCL 4010). The applied climate conditions are shown in Table 2. In one test run the samples have been stored above a saturated $\mathrm{NaNO}_{2}$ solution (Climate A in Table 2) [22].

The surface area of the samples exposed to the atmosphere stayed constant during the test runs. Volume reduction due to evaporation resulted only in reduction of sample height and not in reduction of the drying surface area. After drying the samples were stored in closed polystyrene containers without gas exchange with atmosphere. Three individual samples of $10 \mathrm{~g}$ liquid water glass were dried at each parameter variation of climate and type of water glass. The standard deviation of a single determination of water content was lower than $0.3 \mathrm{wt} \%$. Drying times between 14 and 84 days were applied. Within this time period the samples were weighed in intervals, in the earlier experimental stage daily, later twice a week. The weight loss of the sodium silicate solutions was used to calculate the residual water content. Some of the samples were used for other investigations. Samples for atomic force microscopy (AFM) were cut with a low speed saw (Isomet, Buehler, Düsseldorf, Germany) with water free sawing liquid into appropriate sizes of about $1 \times 1 \mathrm{~cm}^{2}$. The sawing liquid was removed with 
Table 1. Compositions, pH, density, refractive index and viscosity of the investigated water glasses.

\begin{tabular}{cccc}
\hline & NaSi2.2 & NaSi3.3 & NaSi3.9 \\
\hline Supplier & Woellner GmbH, Germany & Carl Roth GmbH, Germany & BASF, Germany \\
$\mathrm{Na}_{2} \mathrm{O}$ content in wt\% & 12.43 & 8.48 & 5.98 \\
$\mathrm{SiO}_{2}$ content in wt\% & 26.3 & 27.42 & 22.76 \\
$R_{m}$ & 2.18 & 3.33 & 3.92 \\
$\mathrm{pH}$ & 12.7 & 12.2 & 11.96 \\
Density in g/cm & 1.47 & 1.36 & 1.27 \\
Refractive index & 1.407 & 1.390 & 20 \\
Viscosity in mPa.s & 65 & 81 & \\
\hline
\end{tabular}

Table 2. Temperature $T$ and water vapour pressure $\mathrm{p}\left(\mathrm{H}_{2} \mathrm{O}\right)$ of drying climates; ambient pressure; the number of independent drying test runs is stated in parentheses.

\begin{tabular}{ccccccc}
\hline$T$ in ${ }^{\circ} \mathrm{C} \downarrow$ & $\mathrm{p}\left(\mathrm{H}_{2} \mathrm{O}\right)$ in $\mathrm{kPa} \rightarrow$ & 4.62 & 5.02 & 10.04 & 20.07 & 40.14 \\
\hline 40 & & $\mathrm{~A}(1)$ & & & \\
60 & & $\mathrm{~B} \mathrm{(3)}$ & $\mathrm{D}(3)$ & $\mathrm{E}(2)$ & $\mathrm{F}(3)$ \\
80 & & $\mathrm{C}(3)$ & & \\
95 & & $\mathrm{G}(2)$ & \\
\hline
\end{tabular}

ethanol. AFM measurements were performed with an Extended MultiMode (Digital Instruments, now Bruker, Santa Barbara, CA, USA) in contact mode applying a constant set-point force between the probing tip at a cantilever and the sample. The force acting between the tip and the surface, measured by the deflection of the cantilever, is kept constant by controlling the vertical displacement of the sample by means of a feedback-loop. During the scan the vertical displacements, needed to keep the force constant, are displayed as "height image" while the remaining deflection (error signal of the feedback-loop) is displayed as "deflection image", which is very sensitive to small topographical changes.

\section{Results and Discussion}

\subsection{Drying Kinetics}

After drying the materials were solid, transparent and amorphous, at least at room temperature. Only after very long drying times some materials became opaque. In former experiments e.g. [15] this was attributed to cracking and/or formation of small gas bubbles. The masses of the samples reached nearly weight constancy after about 14 to $28 \mathrm{~d}$, depending on climate. The results were used to calculate the residual $\mathrm{H}_{2} \mathrm{O}$ content of the drying materials. Figure 1 shows the development of the residual water content of the three different liquid water glasses in climate $\mathrm{D}\left(T=80^{\circ} \mathrm{C}\right.$ and $\left.\mathrm{p}\left(\mathrm{H}_{2} \mathrm{O}\right)=10.01 \mathrm{kPa}\right)$. The data on water contents have been evaluated by a time law which is typical of a first order reaction:

$$
c_{a}=A_{0} \cdot \mathrm{e}^{-k t}+c_{\infty},
$$

with:

$C_{a}$ : actual water content in wt\% (of the dried sample),

$A_{0}$ : prefactor or fitting parameter,

$k$ : rate constant,

$t$ : drying time in $\mathrm{d}$, and

$c_{\infty}$ : the final water content in wt\%.

A least square refinement was used to fit the parameters of the rate law to the experimental data. In the first days of the drying process the fit is not optimal. This is probably due to the transition from the liquid state to the solid state which changes the kinetics. Therefore, the time law is applied for drying times exceeding three days. 
In later test runs drying times of $14 \mathrm{~d}$ were sufficient to calculate $c_{\infty}$. The fitted curves are included in Figure 1. Only at very humid conditions $\left(80^{\circ} \mathrm{C}\right.$ and $\left.40.53 \mathrm{kPa}\left(\mathrm{H}_{2} \mathrm{O}\right)\right)$ the water contents of the drying materials did not follow the proposed rate law. At these humidity conditions the water content first rose with drying time and thenafter more than $30 \mathrm{~d}$-decreased a bit. In these specific test runs the three water glasses stayed liquid during drying at $80^{\circ} \mathrm{C}$, but NaSi3.3 and NaSi3.9 became solid after cooling to room temperature. In the latter cases the liquid to solid transition could be followed by visible inspection. Samples dried at other climates were solid, transparent and amorphous even at drying temperatures. The fitted end values of $c_{\infty}$ of the water contents are reported in Table 3 and have been used for further evaluation. While $c_{\infty}$ was quite stable during a single test run, the repeatability of the determination was worse: deviations up to $2.6 \mathrm{wt} \%$ were observed, especially in more humid climates. The final $\mathrm{H}_{2} \mathrm{O}$ content is related to drying temperature at a constant water vapour pressure, e.g. of $5.07 \mathrm{kPa}$ as displayed in Figure 2. As expected, the residual water content decreased with increasing temperature (Figure 2) and with decreasing water vapour pressure (data in Table 3). The final water contents depend on $R_{m}$ and decrease in the order NaSi2.2 > NaSi3.3 > NaSi3.9, when the other conditions remain constant. The rate constants $\left(k\right.$ ) did not clearly depend on $\mathrm{H}_{2} \mathrm{O}$ vapour pressure or drying temperature. This is due to differences of geometry, convection and forced flow of atmosphere in the different applied drying chambers.

\subsection{Atomic Force Microscopy}

Figure 3(a) shows the surface of a dried NaSi2.2 sample imaged by the height signal in contact mode. Circular objects with a diameter of 80 to $200 \mathrm{~nm}$ can be seen. The deflection signal of the same sample area is shown in

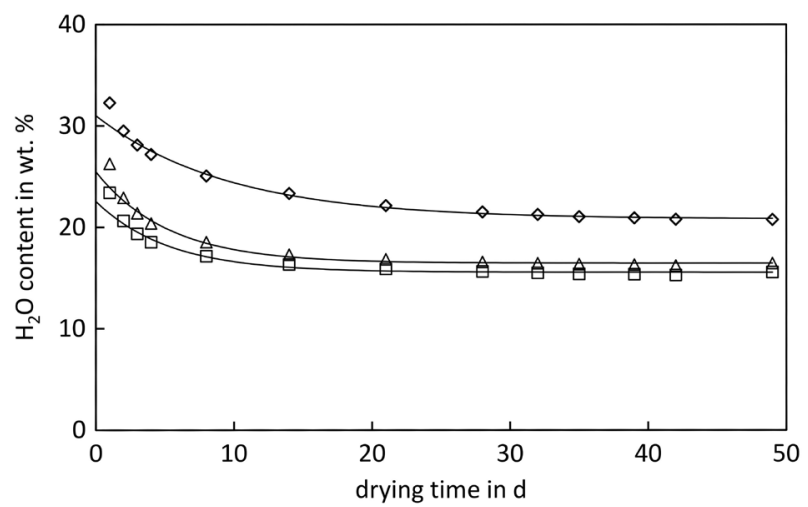

Figure 1. $\mathrm{H}_{2} \mathrm{O}$ content of dried $\mathrm{NaSi} 2.2(\diamond) \mathrm{NaSi} 3.3(\Delta)$ $\mathrm{NaSi3.9}(\square)$ at $\mathrm{p}\left(\mathrm{H}_{2} \mathrm{O}\right)=10.01 \mathrm{kPa}$ and $80^{\circ} \mathrm{C}$ (climate D) as a function of drying time compared with first order rate law $(-)$.

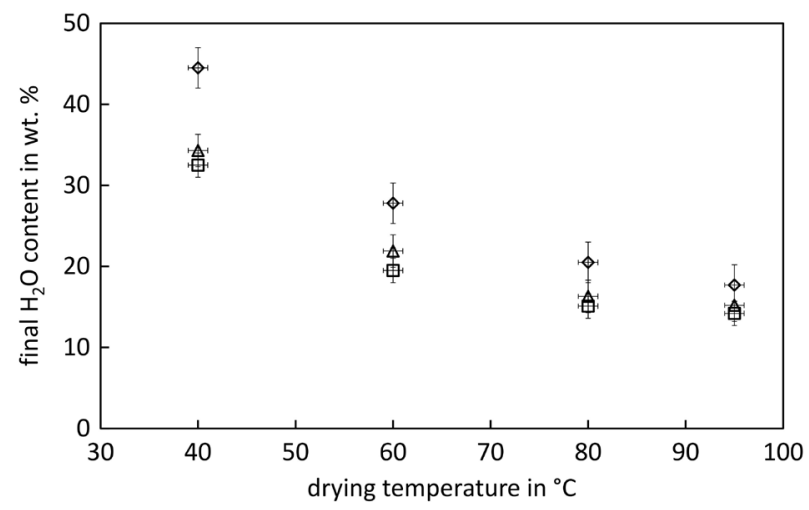

Figure 2. Final $\mathrm{H}_{2} \mathrm{O}$ content $c_{\infty}$ of dried water glasses as a function of drying temperature; $\mathrm{H}_{2} \mathrm{O}$ vapour pressure $=5.07$ $\mathrm{kPa}\left(4.56 \mathrm{kPa}\right.$ at $\left.40^{\circ} \mathrm{C}\right) ; \diamond: \mathrm{NaSi} 2.2 ; \Delta: \mathrm{NaSi} 3.3$; $\square: \mathrm{NaSi} 3.9$. 
Table 3. Final $\mathrm{H}_{2} \mathrm{O}$ contents $c_{\infty}$ for the applied drying climates (temperature and water vapour pressure) after reaching equilibrium.

\begin{tabular}{|c|c|c|c|c|c|}
\hline Climate & Temperature $T$ in ${ }^{\circ} \mathrm{C}$ & $\begin{array}{c}\text { Water vapour } \\
\text { pressure } \mathrm{p} \text { in } \mathrm{kPa}\end{array}$ & $\begin{array}{c}\mathrm{NaSi} 2.2 \\
c_{\infty} \text { in wt\% }\end{array}$ & $\begin{array}{c}\text { NaSi3.3 } \\
c_{\infty} \text { in wt } \%\end{array}$ & $\begin{array}{c}\mathrm{NaSi} 3.9 \\
\boldsymbol{C}_{\infty} \text { in wt\% }\end{array}$ \\
\hline A & 40 & 4.56 & 44.5 & 34.3 & 32.5 \\
\hline B & 60 & 5.07 & $28.2 \pm 1.2$ & $22.3 \pm 0.8$ & $19.5 \pm 0.3$ \\
\hline $\mathrm{C}$ & 80 & 5.07 & $21.1 \pm 0.6$ & $16.3 \pm 0.6$ & $15.5 \pm 0.5$ \\
\hline $\mathrm{D}$ & 80 & 10.01 & $21.0 \pm 0.6$ & $16.4 \pm 0.5$ & $15.9 \pm 1.2$ \\
\hline $\mathrm{E}$ & 80 & 20.03 & $27.6 \pm 2.0$ & $21.5 \pm 1.0$ & $17.6 \pm 2.5$ \\
\hline $\mathrm{F}$ & 80 & 40.53 & $52.7 \pm 2.6$ & $36.0 \pm 1.5$ & $33.2 \pm 0.3$ \\
\hline G & 95 & 5.07 & 18.1 & $15.0 \pm 0.5$ & $12.7 \pm 1.5$ \\
\hline
\end{tabular}
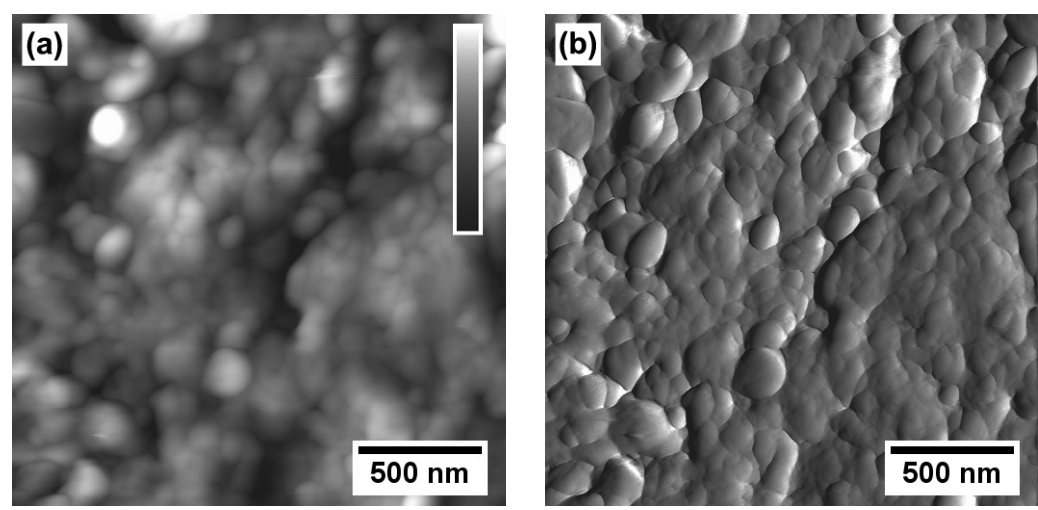

Figure 3. AFM height (a) and deflection (b) images of NaSi2.2 dried $35 \mathrm{~d}$ in climate $\mathrm{D}$ at $80^{\circ} \mathrm{C}$ and an $\mathrm{H}_{2} \mathrm{O}$ vapour pressure of $10.01 \mathrm{kPa}$; residual water content of the specific sample was $20.5 \mathrm{wt} \%$; the grey scale in (a) is $120 \mathrm{~nm}$ and gives information on the depth profiles of the sample area.

Figure 3(b). In this mode the interfaces separating the objects can be seen more clearly. As a consequence the deflection signal was used as the main information source. Figure 4 shows the deflection signal of the surface of a dried NaSi3.3 sample. The spherical objects have sizes between 50 and $300 \mathrm{~nm}$. The surface looks more heterogeneous and the lines separating the objects lack definition in comparison to the NaSi2.2 sample. Figure 5 shows the surface area of an NaSi3.9 sample imaged with the height signal (left) and the deflection signal (right). There are objects with sizes up to $1300 \mathrm{~nm}$ with a mean value of $790 \mathrm{~nm}$. This image of NaSi3.9 allowed size statistics by measuring the diameters of 100 particles: the particle size distribution is broad and looks like a normal distribution (Figure 6). Therefore, it is supposed that the spheres in the AFM images show the original size of the particles and not sections of the spheres [23].

\subsection{Capillary Forces}

The weight constancy after long drying times suggests that a thermodynamic equilibrium between gas phase and dried materials is reached: the vapour pressure of the dried sodium silicate materials is equal to the $\mathrm{H}_{2} \mathrm{O}$ vapour pressure of the drying climate.

The Thomson-Freundlich equation [19] [20] relates equilibrium vapour pressure in a capillary system with the capillary radius in the following way:

$$
(k) p_{V}=p_{0} \cdot \mathrm{e}^{\left(\frac{-2 \cdot V_{\mathrm{mol}} \cdot \gamma_{\mathrm{LV}} \cdot \cos \theta}{R \cdot T \cdot r}\right)},
$$

with

$p_{V}$ : actual water vapour pressure in drying atmosphere, 


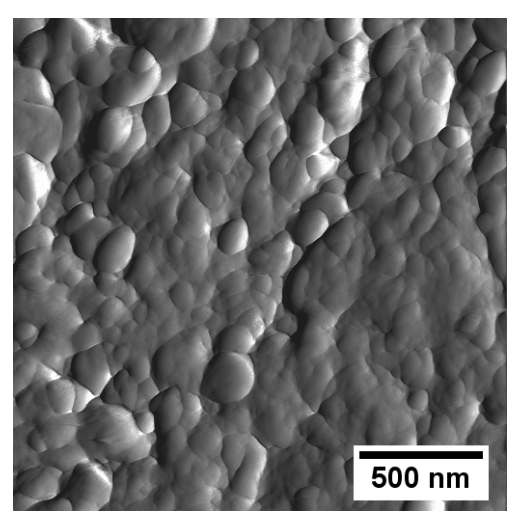

Figure 4. AFM deflection image of $\mathrm{NaSi} 3.3$ dried $35 \mathrm{~d}$ in climate $\mathrm{D}$ at $80^{\circ} \mathrm{C}$ and an $\mathrm{H}_{2} \mathrm{O}$ vapour pressure of $10.01 \mathrm{kPa}$; residual water content of the specific sample was $16.4 \mathrm{wt} \%$.
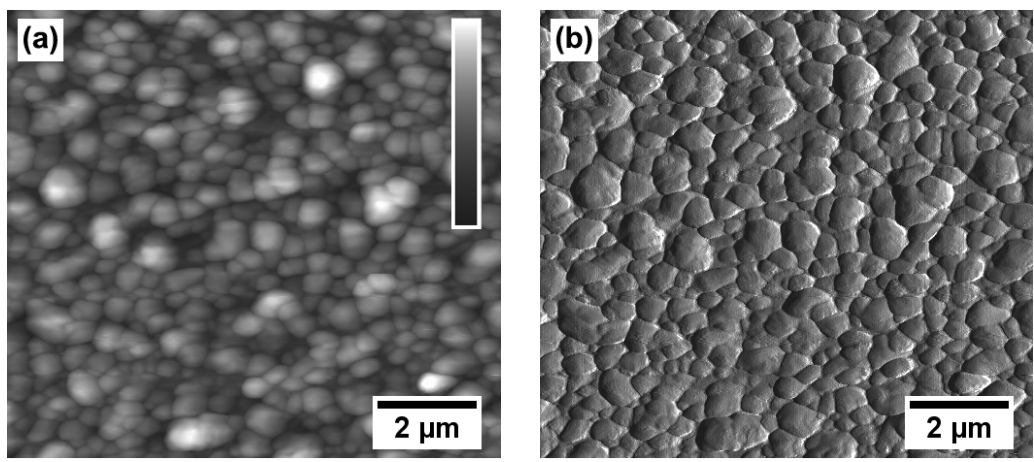

Figure 5. AFM height image (a) and deflection image (b) of NaSi3.9 dried $39 \mathrm{~d}$ in climate $\mathrm{E}$ at $80^{\circ} \mathrm{C}$ and an $\mathrm{H}_{2} \mathrm{O}$ vapour pressure of $20.03 \mathrm{kPa}$; residual water content of the specific sample was $19.8 \mathrm{wt} \%$; the grey scale of the height image is $150 \mathrm{~nm}$.

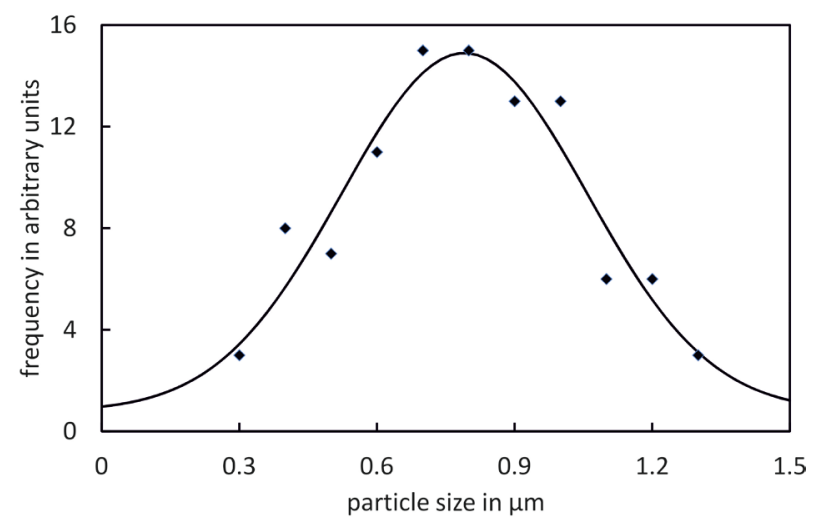

Figure 6. Particle size distribution of NaSi3.9; derived from AFM deflection image in Figure 5; particle statistics and fit according to Gaussian distribution.

$p_{0}: \quad$ vapour pressure of $\mathrm{H}_{2} \mathrm{O}$ at the equilibrium temperature $T$,

$V_{\text {mol }}$ : molar volume of liquid $\mathrm{H}_{2} \mathrm{O}$,

$\gamma_{\mathrm{LV}}$ : $\quad$ surface tension between liquid $\mathrm{H}_{2} \mathrm{O}$ and atmosphere,

$\theta$ : $\quad$ contact angle between liquid and solid,

$R$ : $\quad$ ideal gas constant,

$T: \quad$ absolute temperature, and 
$r$ : $\quad$ pore radius.

Values for surface tension were taken from [24]. The molar volume of water was calculated from density data [25]. The applied data and the calculated capillary diameters are listed in Table 4. The contact angle $\theta$ of water on silica particles depends on the surface density of silanol groups [26]. For colloids in equilibrium with aqueous solution most authors assume the contact angle to be zero e.g. [19], which is assumed here, too.

If the vapour pressure of the applied climate is equal to the vapour pressure of the sodium silicate materials dried at $80^{\circ} \mathrm{C}$ and $5.07 \mathrm{kPa}$, the vapour pressure of $\mathrm{H}_{2} \mathrm{O}$ is reduced from $47.3 \mathrm{kPa}$ to $5.07 \mathrm{kPa}$ which is a reduction by roughly $90 \%$. Figure 7 shows the relation between water content and capillary diameter at constant drying temperature, whereas Figure 8 shows the relation at constant water vapour pressure. Except for climates with high relative humidity (A and F) capillary diameters between 0.5 and $2.0 \mathrm{~nm}$ have been calculated. The accuracy of the $c_{\infty}$ determination does not affect the particle size, because the Thompson-Freundlich equation does not contain that variable. The accuracy of the capillary diameter depends on the accuracy of the climate camber to control humidity and on the accuracy of the surface energy, which is stated to be better than $0.5 \%$ in [24].

In many cases, structure models for sols and gels are based on the assumption that the colloids are rigid spheres [18], a model which was also used in own studies published before [16]. By atomic force microscopy particle diameters between 50 and $1300 \mathrm{~nm}$ have been detected. These particle diameters are larger than those identified by dynamic light scattering [2] [9]. The conclusion is that larger particles are formed during drying by further aggregation. Capillary diameters between 0.7 and $10 \mathrm{~nm}$ were calculated via the Thomson-Freundlich equation. When the microstructure of the dried water glasses is interpreted—in analogy to [18]—as a random

Table 4. Surface tension $\gamma_{\mathrm{LV}}$ [24] and molar volume $V_{\mathrm{mol}}$ [25] of liquid $\mathrm{H}_{2} \mathrm{O}$ applied to calculate capillary diameter $d$ according to the Thomson-Freundlich equation and capillary pressure $P_{c}$, climates $\mathrm{C}$ to $\mathrm{F}$ have the same temperatures and thus identical values of $\gamma_{\mathrm{LV}}$ and $V_{\mathrm{mol}}$.

\begin{tabular}{ccccc}
\hline Climate & $\gamma_{\mathrm{LV}}$ in $/ \mathrm{m}^{2}$ & $V_{\mathrm{mol}}$ in $\mathrm{cm}^{3} / \mathrm{mol}$ & $d$ in $\mathrm{nm}$ & $P_{c}$ in MPa \\
\hline A & 0.0696 & 18.16 & 4.0 & -70 \\
B & 0.06624 & 18.32 & 1.3 & -210 \\
C & 0.0627 & 18.54 & 0.7 & -350 \\
D & 0.0627 & 18.54 & 1.0 & -240 \\
E & 0.0627 & 18.54 & 1.9 & -130 \\
F & 0.0627 & 18.54 & 10.2 & -250 \\
G & 0.05987 & 18.73 & 0.9 & -460 \\
\hline
\end{tabular}

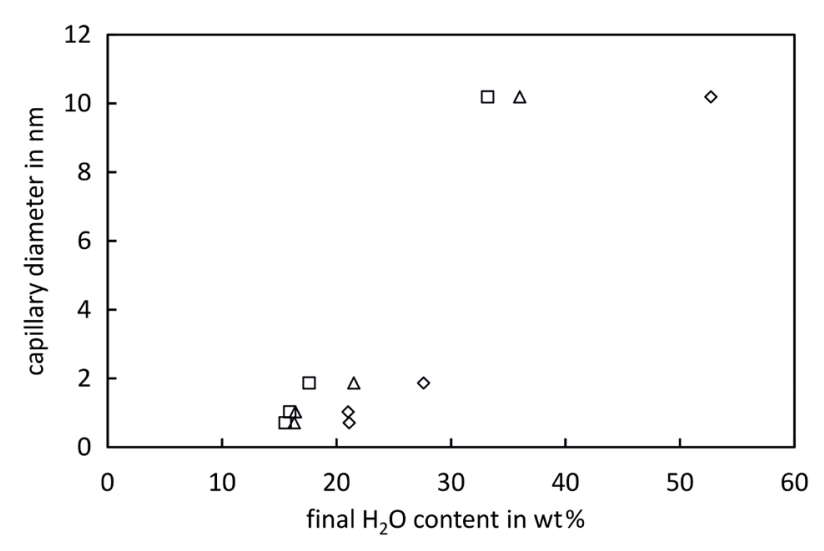

Figure 7. Calculated capillary diameter of dried water glasses as a function of the final $\mathrm{H}_{2} \mathrm{O}$ content $c_{\infty}$ at a constant drying temperature of $80^{\circ} \mathrm{C}$ and different water vapour pressures; $\diamond$ : NaSi2.2; $\Delta$ : NaSi3.3; $\square$ : NaSi3.9. 
close packing of particles, the capillaries are the voids between the particles. If the particles are rigid spheres, the size of the voids is between $40 \%$ and $70 \%$ of the particles diameters, i.e. between 16 and $700 \mathrm{~nm}$. This size range cannot explain the results obtained by the application of the Thomson-Freundlich equation. In earlier measurements ultrafiltration was applied [2]: particles with diameters between 100 and $300 \mathrm{~nm}$ passed $25 \mathrm{~nm}$ filters nearly quantitatively. This was explained by deformation of the particles which was enabled by the aggregation of small primary colloids to weaker bonded aggregates. This deformation of larger aggregates might explain some of the observations. The capillary pressure again depends on the curvature of the liquid surface in the pore system. The Washburn equation [27] can be used also to calculate capillary pressures [19]:

$$
P_{c}=\frac{2 \gamma_{\mathrm{LV}}}{r} \cos \theta \text {, }
$$

with

$P_{c}$ : capillary pressure,

$\gamma_{\mathrm{LV}}$ : surface tension between liquid $\mathrm{H}_{2} \mathrm{O}$ and atmosphere,

$r$ : pore radius, and

$\theta$ : contact angle liquid to solid.

The respective capillary pressures are reported in Table 4, too. Again, $0^{\circ}$ is assumed to be the contact angle. Under these conditions, the capillary pressures contract the liquid pore phase. As a consequence, the volume of the solid is reduced. Pressures up to $460 \mathrm{MPa}$ might be able to press the water out of the pores, compress the capillary system and deform the aggregates. The microstructure shown in the AFM micrographs can be explained by the suggested deformations. The deformation mechanism is illustrated in a two-dimensional sketch in Figure 9. From these suggestions it is concluded that the capillary pressures exceed the stresses necessary for plastic deformation. The differences to the "normal" drying processes of gels as described in [19] can also be explained by deformation. The capillary forces deform the drying water glass in a way that the volume occupied

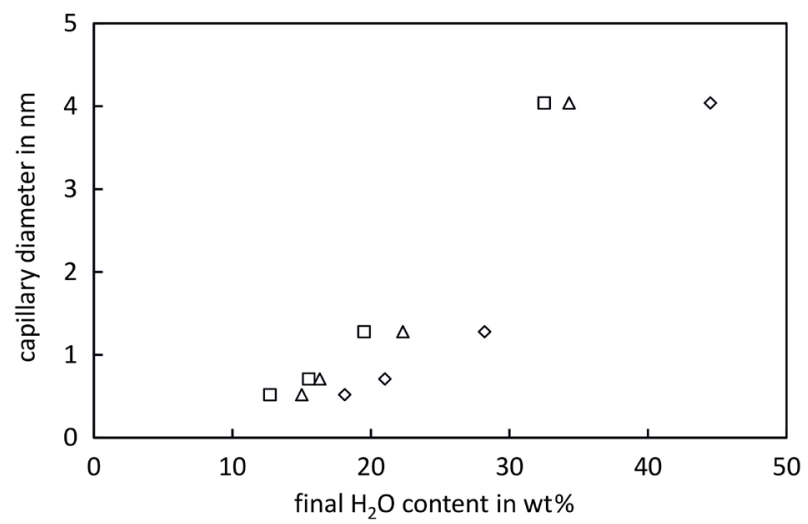

Figure 8. Calculated capillary diameter of dried water glasses as a function of final $\mathrm{H}_{2} \mathrm{O}$ content $c_{\infty}$ at a constant $\mathrm{H}_{2} \mathrm{O}$ vapour pressure of $4.56 \mathrm{kPa}\left(\right.$ at $40^{\circ} \mathrm{C}$ ) or $5.07 \mathrm{kPa}$ (at $60^{\circ} \mathrm{C}$ to $\left.95^{\circ} \mathrm{C}\right) ; \diamond: \mathrm{NaSi} 2.2 ; \Delta: \mathrm{NaSi3.3}$; $\square: \mathrm{NaSi3.9.}$

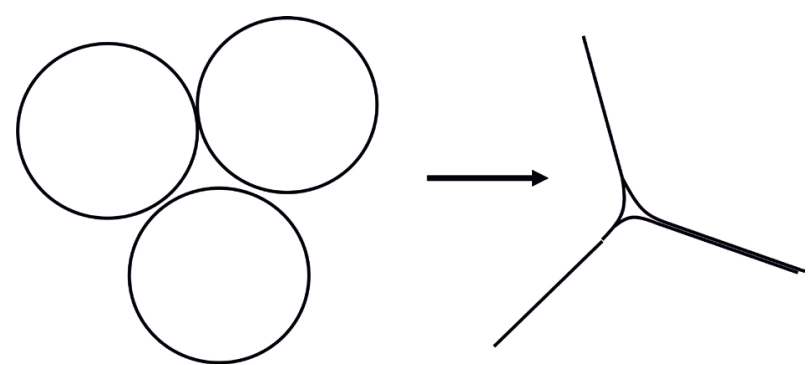

Figure 9. Structure formation by compressing deformable colloids. 
by water is always equal to the pore volume. Under this assumption, the difference between water vapour pressure of the capillary system and the water vapour pressure of the drying atmosphere controls the drying rate at constant temperature, surface area of drying materials and atmospheric flow conditions. The water vapour pressure of the capillary system is reduced during drying so that a first order reaction rate is observed, although the drying morphology of the water glass is typical of the constant rate period of the drying process described in [19].

\section{Conclusions}

The later stages of the drying of water glasses can be explained by a first order rate law. Driving force of the drying process is the difference between water vapour pressure of the drying solid and the water vapour pressure of the atmosphere surrounding the drying solid. Drying stops when both vapour pressures become equal. The colloidal microstructure of the dried materials was confirmed by atomic force microscopy. The microstructure is transformed during drying first to an amorphous solid made up by spherical colloids which-upon further drying - are deformed due to capillary forces. Therefore, the observed microstructures fit to a drying process based on the following transitions:

$$
\text { sol } \leftrightarrow \text { aggregate/colloid gel } \leftrightarrow \text { capillary solid with deformed aggregates. }
$$

The capillary pores have sizes between 0.7 and $10 \mathrm{~nm}$. The deformed microstructure can be visualized by atomic force microscopy and reveals aggregate sizes between 50 and $1300 \mathrm{~nm}$. The drying in controlled climates enhances the accuracy of the measurements.

\section{Acknowledgements}

The experimental assistance of S. Brinke is gratefully acknowledged. Thanks are also due to the state SaxonyAnhalt for funding a new climate chamber.

\section{References}

[1] Vail, J.G. (1952) Soluble Silicates-Their Properties and Uses, Vol. 1, Chemistry. Reinhold, New York.

[2] Roggendorf, H., Grond, W. and Hurbanic, M. (1996) Structural Characterization of Concentrated Alkaline Silicate Solutions by ${ }^{29}$ Si-NMR Spectroscopy, FT-IR Spectroscopy, Light Scattering, and Electron Microscopy-Molecules, Colloids, and Dissolution Artefacts. Glass Sci. Technol., 69, 216-231.

[3] Iler, R.K. (1979) The Chemistry of Silica. Solubility, Polymerisation, Colloid and Surface Properties, and Biochemistry. Wiley-Interscience Publication, New York.

[4] Falcone, J.S. (2005) Silicon Compounds, Anthropogenic Silica and Silicates. In: Kirk-Othmer Encyclopedia of Chemical Technology, Wiley Online Library, New York. http://dx.doi.org/10.1002/0471238961.1925142006011203.a01.pub2

[5] Yoshida, A. (2006) Silica Nucleation, Polymerization, and Growth Preparation of Monodisprsed Sols. In: Bergna, H.E. and Roberts, W.O., Eds., Colloidal Silica: Fundamentals and Applications, Surfactant Science Series 131, 47-56.

[6] Iler, R.K. (1982) Colloidal Components in Solutions of Sodium Silicate. In: Falcone, J.S., Ed., Soluble Silicates, ACS Symposium Series, 194, 95-114.

[7] Healey, T. (2006) Stability of Aqueous Silica Sols. In: Bergna, H.E. and Roberts, W.O., Eds., Colloidal Silica: Fundamentals and Applications, Surfactant Science Series, 131, 247-252.

[8] Bahlmann, E.K.F., Harris, R.K., Metcalfe, K., Rockliffe, J.W. and Smith, E.G. (1997) Silicon-29 NMR Self-Difusion and Chemical-Exchange Studies of Concentrated Sodium Silicate Solutions. Journal of the Chemical Society, Faraday Transactions, 93, 93-98. http://dx.doi.org/10.1039/a604878a

[9] Böschel, D., Janich, M. and Roggendorf, H. (2003) Size Distribution of Colloidal Silica in sodium Silicate Solutions Investigated by Dynamic Light Scattering and Viscosity Measurements. Journal of Colloid and Interface Science, 267, 360-368. http://dx.doi.org/10.1016/j.jcis.2003.07.016

[10] Nordström, J., Sundblom, A., Jensen, G.V., Pedersen, J.S., Palmqvist, A. and Matic, A. (2013) Silica/Alkali Ratio Dependence of the Microscopic Structure of Sodium Silicate Solutions. Journal of Colloid and Interface Science, 397, 917. http://dx.doi.org/10.1016/j.jcis.2013.01.048

[11] Tognonvi, M.T., Massiot, D., Lecomte, A. and Rossignol, S. (2010) Identification of Solvated Species Present in Concentrated and Dilute Sodium Silicate Solutions by Combined ${ }^{29}$ Si NMR and SAXS Studies. Journal of Colloid and In- 
terface Science, 352, 309-315. http://dx.doi.org/10.1016/j.jcis.2010.09.018

[12] Halasz, I., Li, R., Agarwal, M. and Miller, N. (2007) Monitoring the Structure of Water Soluble Silicates. Catalysis Today, 126, 196-202. http://dx.doi.org/10.1016/j.cattod.2006.09.032

[13] Trautz, V., Gärtner, F., Körner, H.H., Linke, R., Weber, H. and Wirth, H. (1978) Fire-Protective Materials. Patent No. DE 2703022.

[14] Dent Glasser, L.S. and Lee, C.K. (1973) Drying of Sodium Silicate Solutions. Journal of Applied Chemistry and Biotechnology, 21, 127-133. http://dx.doi.org/10.1002/jctb.5020210502

[15] Roggendorf, H. and Böschel, D. (2002) Hydrous Sodium Silicate Glasses Obtained by Drying Sodium Silicate Solutions. Journal of Glass Science and Technology, 75, 103-111.

[16] Roggendorf, H., Böschel, D. and Trempler, J. (2001) Structural Evolution of Sodium Silicate Solutions Dried to Amorphous Solids. Journal of Non-Crystalline Solids, 293-295, 752-757. http://dx.doi.org/10.1016/S0022-3093(01)00785-2

[17] Pusey P.N. and Van Megen, W. (1990) The Glass Transition of Hard Spherical Colloids. Berichte der Bunsengesellschaft für physikalische Chemie, 94, 225-229. http://dx.doi.org/10.1002/bbpc.19900940306

[18] Cann, J.Y. and Cheek, D.L. (1925) Relationship between Composition and Boiling Point of Aqueous Solutions of Sodium Silicate. Industrial \& Engineering Chemistry, 17, 512-514. http://dx.doi.org/10.1021/ie50185a031

[19] Brinker, C.J. and Scherer, G.W. (1990) Sol-Gel Science. Academic Press, San Diego.

[20] Chiang, Y.-M., Birdie III, D.P. and Kingery, W.D. (1997) Physical Ceramics. John Wiley \& Sons, New York.

[21] Knudsen, M. (1909) Die Gesetze der Molekularströmung und der inneren Reibungsströmung der Gase durch Röhren. Annalen der Physik, 28, 75-130. http://dx.doi.org/10.1002/andp.19093330106

[22] Winston, P.W. and Bates, D.H. (1960) Saturated Solutions for the Control of Humidity in Biological Research. Ecology, 41, 232-237. http://dx.doi.org/10.2307/1931961

[23] Susan, D. (2005) Stereological Analysis of Spherical Particles: Experimental Assessment and Comparison to Laser Diffraction. Metall. Metallurgical and Materials Transactions A, 36, 2481-2492. http://dx.doi.org/10.1007/s11661-005-0122-3

[24] Vargaftik, N.B., Volkov, B.N. and Voljak, L.D. (1983) International Table of the Surface Tension of Water. Journal of Physical and Chemical Reference Data, 12, 817-820. http://dx.doi.org/10.1063/1.555688

[25] Weast, R.C., Ed. (1983) CRC Handbook of Chemistry and Physics. 62nd Edition, CRC Press, Boca Raton.

[26] Muster, T.H., Prestidge, C.A. and Hayes, R.A. (2001) Water Adsorption Kinetics and Contact Angles of Silica Particles. Colloids and Surfaces A: Physicochemical and Engineering Aspects, 176, 253-266. http://dx.doi.org/10.1016/S0927-7757(00)00600-2

[27] Washburn, E.W. (1921) The Dynamics of Capillary Flow. Physical Review, 17, 273-283. http://dx.doi.org/10.1103/PhysRev.17.273 
Scientific Research Publishing (SCIRP) is one of the largest Open Access journal publishers. It is currently publishing more than 200 open access, online, peer-reviewed journals covering a wide range of academic disciplines. SCIRP serves the worldwide academic communities and contributes to the progress and application of science with its publication.

Other selected journals from SCIRP are listed as below. Submit your manuscript to us via either submit@scirp.org or Online Submission Portal.
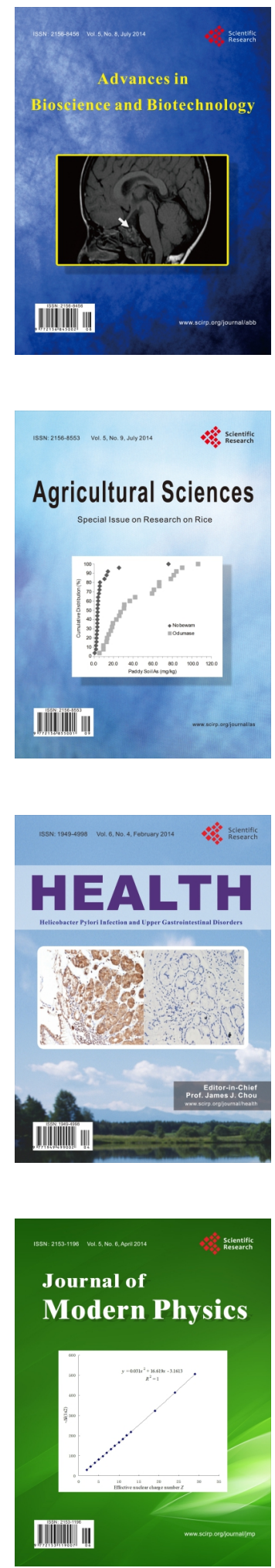
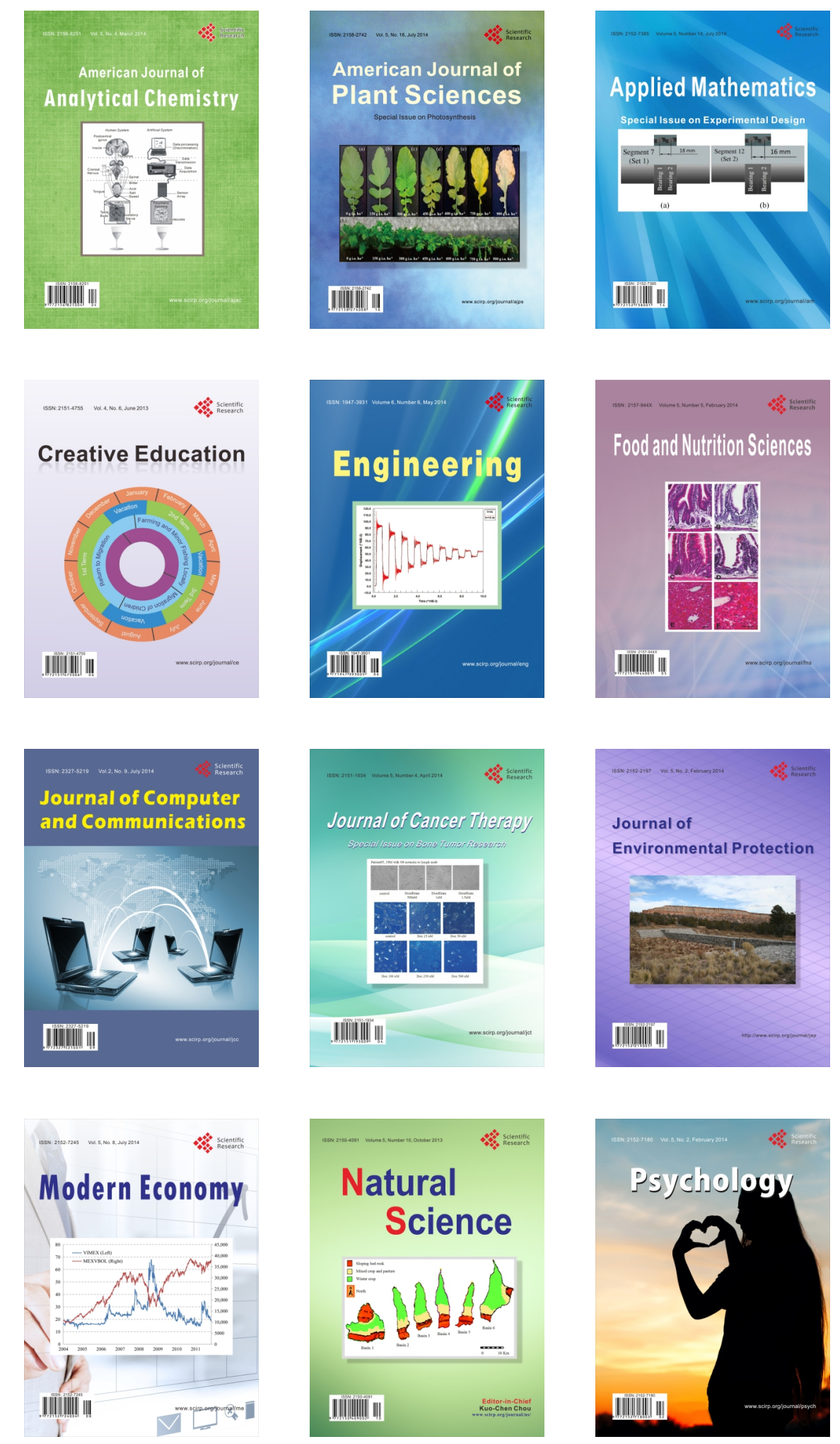